Kumawula, Vol. 3, No.1, April 2020, Hal 116 - 128 DOI:http://10.24198/kumawula.v3i1.24598

ISSN 2620-844X (online)

Tersedia online di http://jurnal.unpad.ac.id/kumawula/issue/view

\title{
STRATEGI PENINGKATAN PENYADARAN ISU LINGKUNGAN BAGI SISWA SEKOLAH DASAR MELALUI PERMAINAN ULAR TANGGA: KONTRIBUSI UNPAD UNTUK PROGRAM CITARUM HARUM
}

\author{
Ida Widianingsih \\ Pusat Studi Desentralisasi dan Pembangunan Partisipatif, Fakultas Ilmu Sosial dan Ilmu Politik, \\ Universitas Padjadjaran \\ ida.widianingsih@unpad.ac.id
}

\begin{abstract}
ABSTRAK
Pemerintah Indonesia menggagas Program Citarum Harum pada akhir 2017 sebagai jawaban atas kritik rusaknya sungai strategis nasional tersebut. Upaya percepatan penanggulangan kerusakan Sungai Citarum memerlukan peran serta semua pihak, termasuk akademisi. Universitas Padjadjaran memperkenalkan program Kuliah Kerja Nyata (KKN Citarum Harum) pada medio tahun 2019 sebagai kontribusi nyata dunia akademik terhadap isu kerusakan sungai Citarum. Gagasan utama kegiatan ini adalah memfasilitasi berbagai kegiatan peduli Citarum Harum di 40 Desa prioritas DAS Citarik. Artikel ini membahas tentang kegiatan kelompok mahasiswa KKN di Desa Cipanjalu dalam mensosialisasikan isu kerusakan Sungai Citarum melalui media permainan ular tangga. Kegiatan tersebut diikuti oleh Siswa Kelas 5 SDN Pasir Luhur, Desa Cipanjalu dan memperoleh respon positif dari siswa, guru, serta kepala sekolah.
\end{abstract}

Kata kunci: Citarum Harum, isu lingkungan, permainan edukasi, KKN Unpad, Desa Cipanjalu

\section{THE STRATEGY TO IMPROVE PRIMARY SCHOOL STUDENTS AWARENESS ON ENVIRONMENTAL ISSUES THROUGH EDUCATION GAME: UNPADS CONTRIBUTION FOR CITARUM HARUM PROGRAM}

\begin{abstract}
The Indonesian Government initiated the Citarum Harum Program at the end of 2017 as the answer to the critique that the strategic national river was degrading. The efforts to deal with the damages done to the Citarum River requires the involvement of everyone, including academics. Padjadjaran University introduced a special Student's Community Engagement Program (Kuliah Kerja Nyata, KKN Tematik Citarum Harum) in the mid of 2019 as the real contribution of the academic world to overcome the degradation of the Citarum River. The main idea behind this program is the facilitation of many Citarum Harum caring activities in 40 priority villages around Citarik Watershed. This article discusses the activities of KKN students in Cipanjalu Village. The students were tasked with socializing the issue of the degradation done to the Citarum River through the snakes and ladders board game. This activity was attended by year 5 students from Cipanjalu National Primary School and gained a positive response from students, teachers, and also the headmaster.
\end{abstract}

Keywords: Citarum Harum, environment issues, education game, KKN Unpad, Cipanjalu Village 


\section{PENDAHULUAN}

Kekuatan sosial media dalam mendorong perubahan kebijakan pemerintah dapat dilihat dari upaya Pemerintah Indonesia dalam menggagas Program Citarum Harum pada akhir 2017 (Agus, 2018; Een, 2018). Sejarah panjang penanganan kerusakan Daerah Aliran Sungai (DAS) Citarum telah dilakukan sejak tahun 1980an, namun berbagai intervensi kebijakan dan program tersebut dinilai belum mampu menyelesaikan kompleksitas masalah pencemaran DAS Citarum, bahkan dari tahun ke tahun kerusakan yang terjadi semakin parah (Samekto \& Rahmadiyanto, 2016; Sarminingsih, 2007; Suharyanto \& Matsushita, 2011).

Pemerintah Jokowi merespon kritik internasional atas rusaknya Citarum melalui penerbitan Peraturan Presiden Nomor 15/ 2018 tentang Percepatan Pengendalian Pencemaran dan Kerusakan DAS Citarum dengan melibatkan semua pemangku kepentingan melalui tahapan-tahapan diskusi baik di tingkat pemerintah pusat, provinsi, kabupaten/kota, swasta, akademisi, dan penggiat lingkungan. Targetnya dalam 7 tahun Citarum mampu lepas dari penilaian sebagai Sungai terkotor di Dunia (Agus, 2018; Yallop, 2014). Pada prakteknya, kebijakan tersebut dilaksanakan melalui pembentukan Lembaga kolaboratif yangmenggabungkan birokrasi dengan militer untuk Bersama-sama mempercepat penanganan Citarum yang dikenal dengan "SATGAS CITARUM HARUM (Satgas Citarum Harum, 2019). Gubernur Jawa Barat selaku Komandan Citarum Harum, Bersama stakeholder pembangunan Jawa Barat menerbitkan Rencana Aksi Nasional Citarum 2019-2014 dengan tujuan ersedianya pedoman pemangku kepentingan dalam penyusunan rencana yang lebih teknis, penyusunan penganggaran, serta sebagai acuan pelaksanaan monitoring dan evaluasi dalam usaha penanganan DAS Citarum (Agus, 2018)

Unpad sebagai salah satu universitas terkemuka di Jawa Barat teah lama melakukan berbagai riset untuk menyekleasaikan isu Citarum, terkait dengan gagasan Percepatan Penanganan Citarum, Unpad mendirikan Citarum Research Center untuk memperkuat riset-riset dan kegiatan-kegiatan yang selama ini dilakukan Unpad. Disamping itu, CRC bergerak aktif bersama dengan stakeholder lain dengan menggunakan pendekatan Pentahelix (CRC 2018; Widianingsih \& Mertens 2019). Dua tahun setelah pelaksanaan Citarum Harum, secara relative program telah dijalankan, namun belum optimal,, utamanya terjadi penumpukan sumberdaya (Pokja Edukasi Satgas Citarum Harum, 2019).

Unpad sendiri menyadari bahwa upaya percepatan penanggulangan kerusakan Sungai Citarum memerlukan peran serta semua pihak, termasuk akademisi. Universitas Padjadjaran 
memperkenalkan program Kuliah Kerja Nyata (KKN Citarum Harum) pada medio tahun 2019 sebagai kontribusi nyata dunia akademik terhadap isu kerusakan sungai Citarum. Gagasan utama kegiatan ini adalah memfasilitasi berbagai kegiatan peduli Citarum Harum di 40 Desa prioritas DAS Citarik.

Gambar 1. Wilayah DAS Citarik

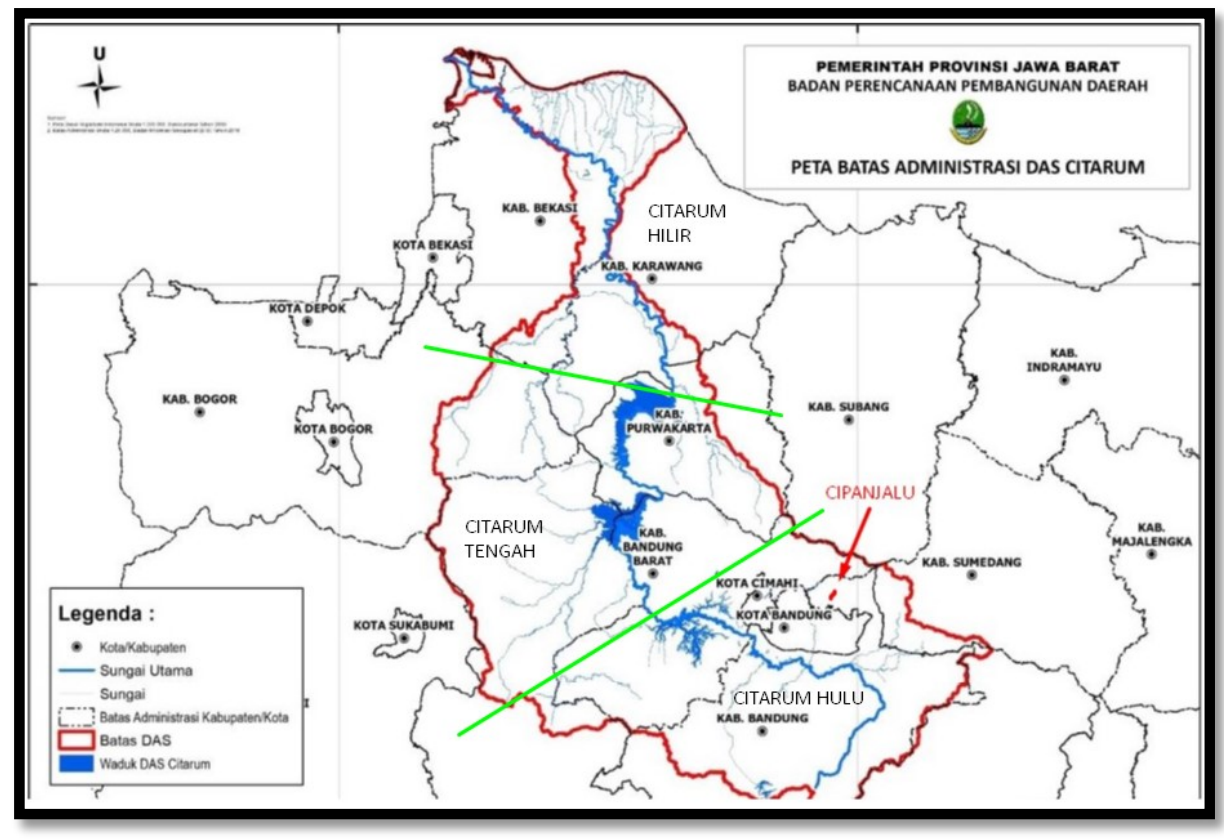

Sumber: Diplah DRPM Unpad 2019a dari Hasil Pengolahan SK.304/MENLHK/PDASHL/ DAS.0/7/2018 tentang Peta Daerah Aliran

Pelaksanaan KKN Tematik Citarum Harum hanya difokuskan di 40 Desa terpilih dengan melibatkan 40 Dosen Pembimbing Lapangan dan 800 orang mahasiswa. Pengembangan Konsep KKN ini dilakukan Tim DRPM Unpad didasarkan pada berbagai kajian yang dilaksanakan Tim Peneliti Unpad sejak tahun 1980an (Parikesit, Takeuchi, Tsunekawa, \& Abdoellah, 2001).

Program Kuliah Kerja Nyata (KKN) Tematik Citarum Harum merupakan program terobosan yang saat ini sedang disempurnakan dalam implementasinya. Kegiatan KKN Tematik Citarum Harum ini diselenggarakan berdasarkan konteks wilayah dan justifikasi isu di lapangan serta upaya pemecahan masalah terkait DAS Citarum. Dalam kegiatan KKN Tematik Citarum Harum, mahasiswa yang menjadi peserta dan dosen yang menjadi pembimbing lapangan, akan bekerja sama dengan berbagai elemen dari masyarakat untuk mengintegrasikan ide dan gagasan untuk membangun solusi implementatif dari permasalahan 
DAS Citarum yang diwujudkan dalam program kerja pada Desa yang menjadi lokasi kegiatan KKN Tematik Citarum Harum.

Secara umum kegiatan KKN Tematik Citarum Harum ini ditujukan untuk memperluas wawasan mahasiswa dan meningkatkabn kepedulian mereka atas problem lingkungan, utamanya terkait dengan isu Pencemaran Citarum. Dsamping itu, mahasiswa KKN didorong melakukan kegiatan aktivasi sosial melalui masyarakat aktif (active citizen) untuk dapat berkontribusi dalam pelestarian lingkungan berkelanjutan.

Gambar 2. Konsep Utama KKN Tematik Citarum Harum Unpad 2019

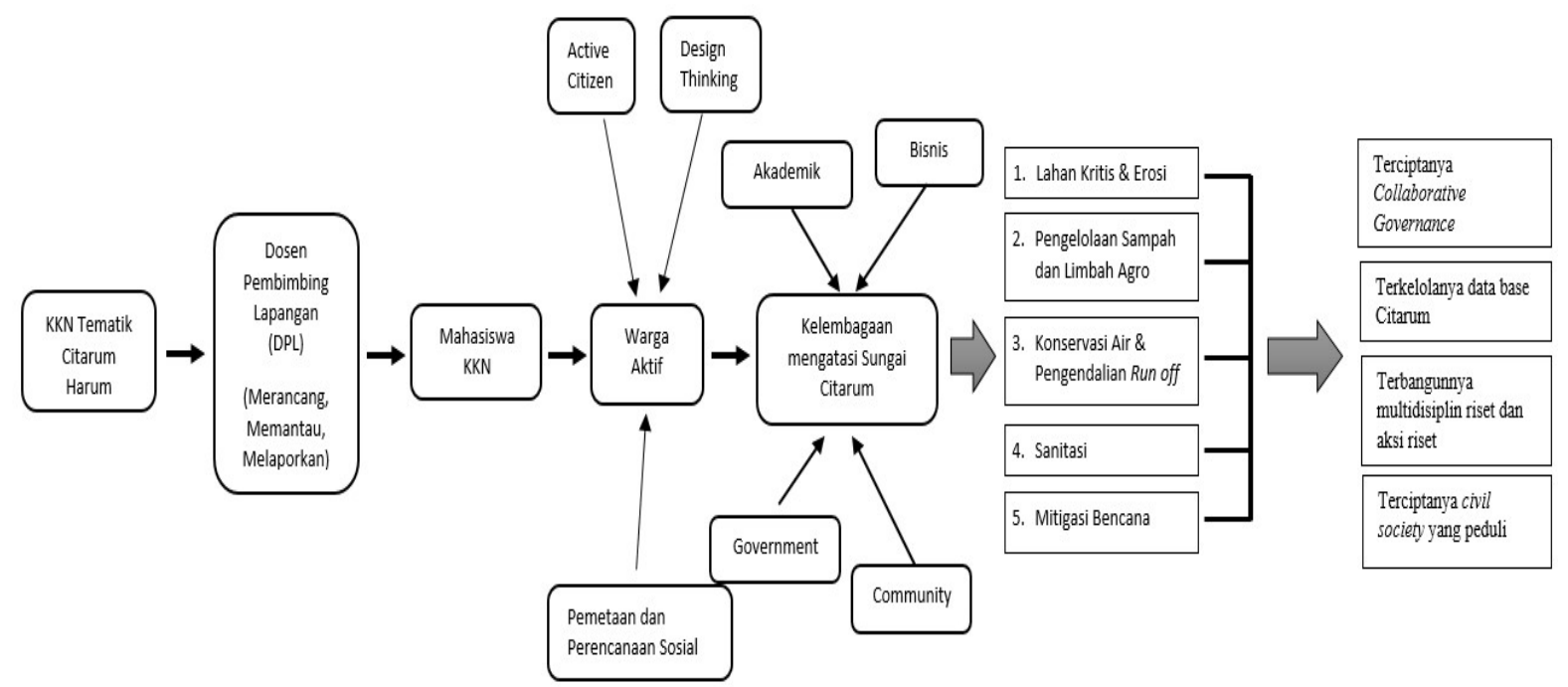

Sumber: DRPM 2019a

Kegiatan KKN di Desa Cipanjalu dilakukan oleh 20 mahasiswa terpilih dari berbagai prodi di Unpad. Proses penentuan mahasiswa peserta KKn dilakukan melalui Call of Action yag didistribusikan di berbagai media daring, Maahasiswa mendaftarkan diri dan memilih DPL untuk diseleksi dan ditempatjkan sesuai kebijakan Universitas (DRPM 2019a)

Gambar 3 Call of Actions Kegiatan KKN Tematik Citarum Harum Unpad 2019 


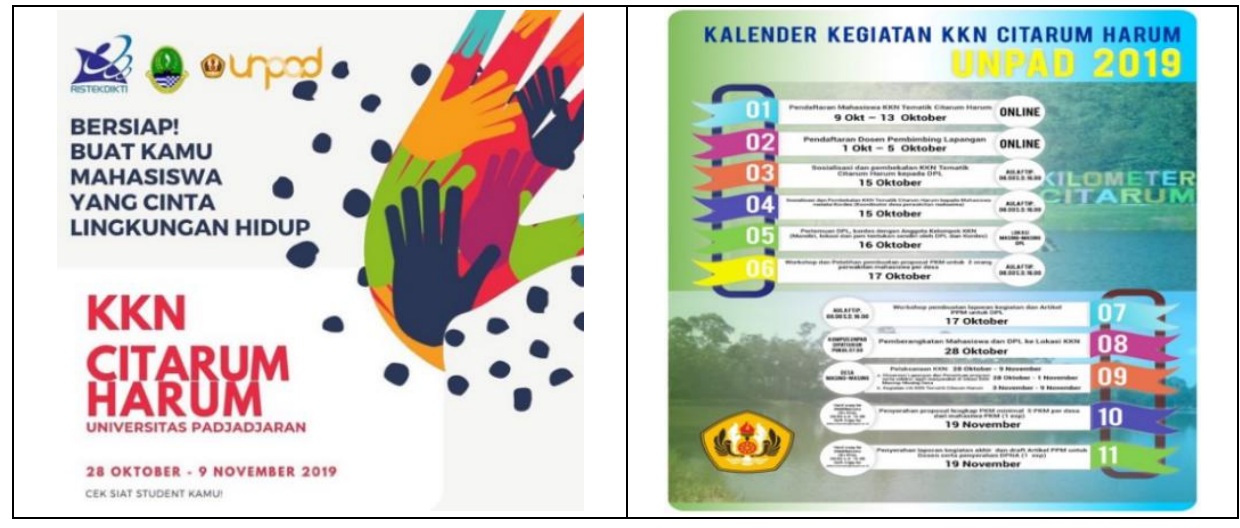

Sumber: DRPM Unpad 2019b

Artikel ini secara spesifik membahas tentang kegiatan kelompok mahasiswa KKN di Desa Cipanjalu dalam mensosialisasikan isu kerusakan Sungai Citarum melalui media permainan ular tangga. Kegiatan tersebut diikuti oleh Siswa Kelas 5 SDN Pasir Luhur, Desa Cipanjalu dan memperoleh respon positif dari siswa, guru, serta kepala sekolah.

\section{METODE}

Secara umum metode yang digunakan dalam KKN Tematik Citarum Harum Unpad 2019 menerapkan Participatory Actions Research (PAR) dengan menggunakan beberapa tools yang diadaptasi dari konsep design thinking dan Active Citizen (DRPM Unpad 2019a). Praktek-praktek Participatory Actions Research (PAR) telah banyak digunakan di berbagai negara dan dipercaya menjadi alternative pendekatan riset yang mampu mendorongterjadinya perubahan positif di masyarakat (McIntyre, 2002; Tashakkori, Teddlie, Tashakkori, \& Teddlie, 2015; Widianingsih \& Morrell, 2007).

Dalam konteks pelaksaan KKN di Desa Cipanjalu, Tim mahasiswa melakukan adaptasi metode dan pendekatan sesuai dengan konteks isu setempat. Pemilihan metode juga terkait dengan keterbatasan waktu kegiatan KKN yang mencakup 9 hari kerja (termasuk upacara pemberangkatan dan kegiata penutupan. Cakupan wilayah Desa lokasi KKN yang cukup luas menyebabkan lamanya proses pengumpulan data lapangan (Rahman 2019).

Metode yang digunakan dalam kegiatan KKN Tematik Citarum Harum 2019 di desa Cipanjaku terdiri dari; Observasi, wawancara kelompok, wawancara mendalam, Focus Group Discussion, diskusi dengan ahli (expert interview). Tools yang digunakan diantaranya, kanvas akar masalah, kanvas peta konteks Desa Cipanjalu, dan kanvas pemetaan kemitraan pentahelix. 


\section{Penggunaan Permainan Ular Tangga bagi Siswa SD dalam Sosialisasi Isu Lingkungan} di Desa Cipanjalu

Desa Cipanjalu merupakan salah satu Desa yang dipilih menjadi untuk melaksanakan kegitaan KKN Tematik CItarum Harum Unpad tahun 2019. Wilayah ini terletak di Kecamatan Cilengkrang Kabupaten Bandung yang merupakan wilayah hsil pemekaran pada tahun 1990 dari Desa Jatimekar, Kelurahan PasirJati Kecamatan Ujungberung Kota Bandung (Rahman, dkk 2019). 
Gambar 4 Peta Wilayah KKN Tematik Citarum Unpad 2019 Harum di Desa Cipanjalu

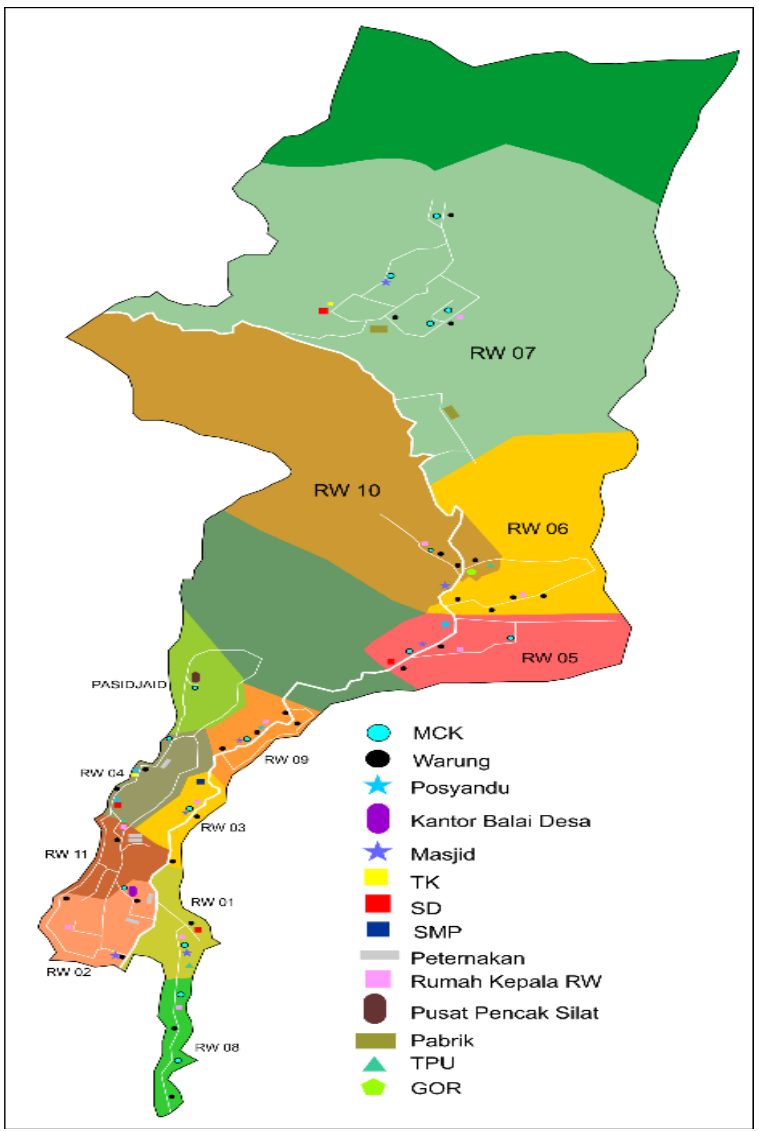

Sumber: Peta Wilayah Desa Cipanjalu, 2019

Secara administratif Desa Cipanjalu terdiri dari 11 RW yang terletak di dataran tinggi Kecamatan Ujung Berung, Kota Bandung. Desa tersebut diapit Gunung Palasari dan Gunung Manglayang. Wilayah ini mayoritas didominasi lahan perkebunan, dan perhutanan dan memiliki kawasan hutan lindung yang memisahkan RW 09 dan RW 05. Tofografi wilayah seperti itu keatas sehingga menciptakan perbedaan yang cukup mencolok antara RW kawasan bawah $(01,02,03,04,08,09,11)$ dan kawasan atas (RW 05, 06, 07,10) (Rahman dkk, 2019).

Saat ini Desa Cipanjalu mencatat penduduk sebanyak 5600 orang, mayoritas penduduk Desa Cipanjalu memiliki mata pencaharian sebagai petani, pekebun, peternak, buruh lepas, dan pedagang. Tingkat pendidikan akhir mayoritas jenjang SMP/SMA.

Berdasarkan observasi yang dilakukan oleh Tim KKN Tematik Citarum Harum Unpad 2019, pada umumnya masyarakat Desa Cipanjalu berpenghasilan rendah, hakl ini boleh jadi terkait dengan tingkat Pendidikan dan profesi mereka.

Disamping itu, kanvas Peta Konteks Desa Cipanjalu menunjukkan masalah kerawanan air sebagai isu utama di Desa Tersebut, sebagaimana terlihat pada gambar berikut: 


\section{Gambar 5 Kondisi dan Potensi Sosial}

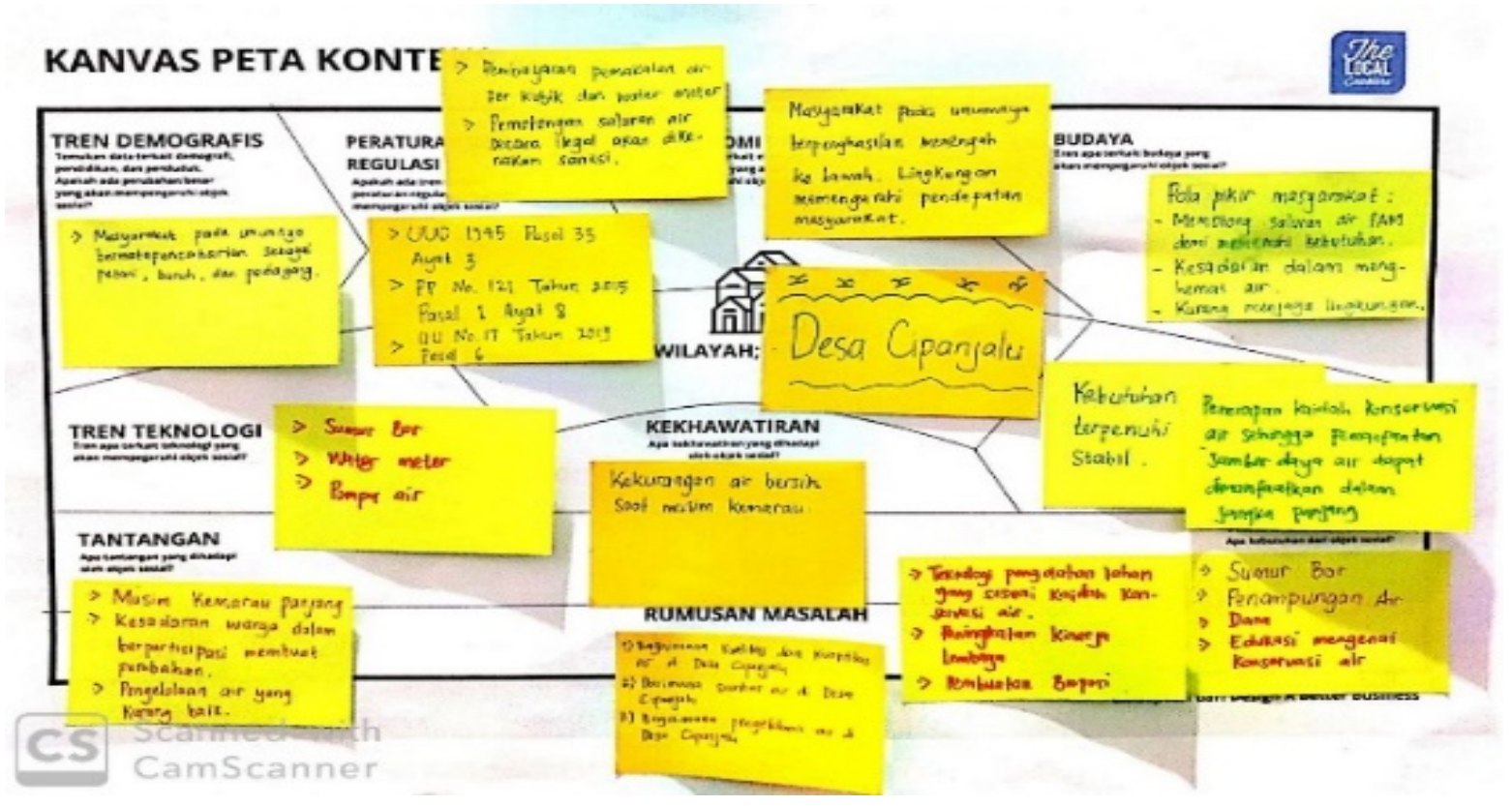

(Rahman dkk, 2019)

Disamping masalah air, pengelolaan sampah di Desa Cipanjalu belum terorganisisr dengan baik, sejauh ini layanan pengelolaan sampah dari Pemkab Bandung belum dapat menjangkau Desa Cipanjalu. Namun demikian, masyarakat sudah memiliki kebiasaan mengelola sampah domestik sendiri, dengan cara dibakar dekat pekarangan rumah. Kebiasaan membakar sampah dianggap warga efektif untuk mengolah sampah (Rahman dkk, 2019)

Untuk sampah yangberasal dari limbah pertanian, sudah mendekati prinsip zero waste., karena masyarakat terbiasa menggunakan limbah pertanian untuk pakan ternak serta pupuk alami di sawah/kebun masing-masing. Pemerintah Desa sendiri secara rutin mengadakan kegiatan Bersama bergotong-royong melalui program "Jumsih” -Jumat bersih di RW 5,6,7,10,11 dan Setiap hari Minggu di RW 4. Menariknya, kegiatan bersih-bersih Bersama hanya dilakukan pada RW-RW di daerah atas yang berkarakter perdesaan (Rahman dkk, 2019)

Walaupun pemerintah teah mengebalkan program pengolahan sampah rumah tangga dengan prisip 3R (Reduce, Reuse, Recycle), belum semua rumah tangga melaksanakan hal tersebut. Bahkan aparat desa mengungkapkan adanya upaya penanganan sampah berkelompok yang dilakukan di salah satu RW dengan melibatkan para pemuda anggota Karang Taruna. Sayangnya upaya tersebut tidak berkelanjutan karena pengelolaan sampah dianggap tidak memberikan keuntungan ekonomi bagi para pengelolanya. 
Kegiatan ini juga mengidentifikasikan kurangnya sosialisasi penanganan sampah dan isu lingkungan di kalangan anak-anak. Hasil wawancara dengan anak-anak sekolah di SDN Pasir Luhur menunjukkan anak-anak SD tidak memahami bagaimana caranya sampah dikelola. Bagi mereka, manfaat pengolahan sampah rendah karena pad aakhirnya sampah akan dibakar sesuai dengan kebiasaan.

Berdasarkan hasil observasi dan wawancara beberapa ibu rumah tangga di beberapa RW, kebiasaan masyarakat dalam mengelola sampah dan menangani isu-isu lingkungan diikuti oleh anak-anak mereka. Saat ini setidaknya terdapat 2 TK, 4 SD dan 1 SMP di Desa Cipanjalu yaitu TK As-Syifa, TK Az-Zahra, SD Pasirluhur, SD Cikapundung 1, SD Cikapundung 2, SD Palintang, dan SMP Cilengkrang.

Dari temuan tersebut, Tim KKN Citarum Harum Desa Cipanjalu mendiskusikan program intervensi untuk edukasi lingkungan bagi siswa SD. Kegiatan tersebut bertujuan untuk memberikan edukasi pada anak-anak SD bterkait dengan isu lingkungan sesuai dengan cakupan program KKN Tematik Citarum Harum Unpad 2019. Tim memutuskan untuk mendisain game edukasi dengan mengadaptasi permainan ular tangga.

Gambar 6 Disain Ular Tangga Lingkungan Karya Mahasiswa KKN Tematik Citarum Harum Unpad 2019

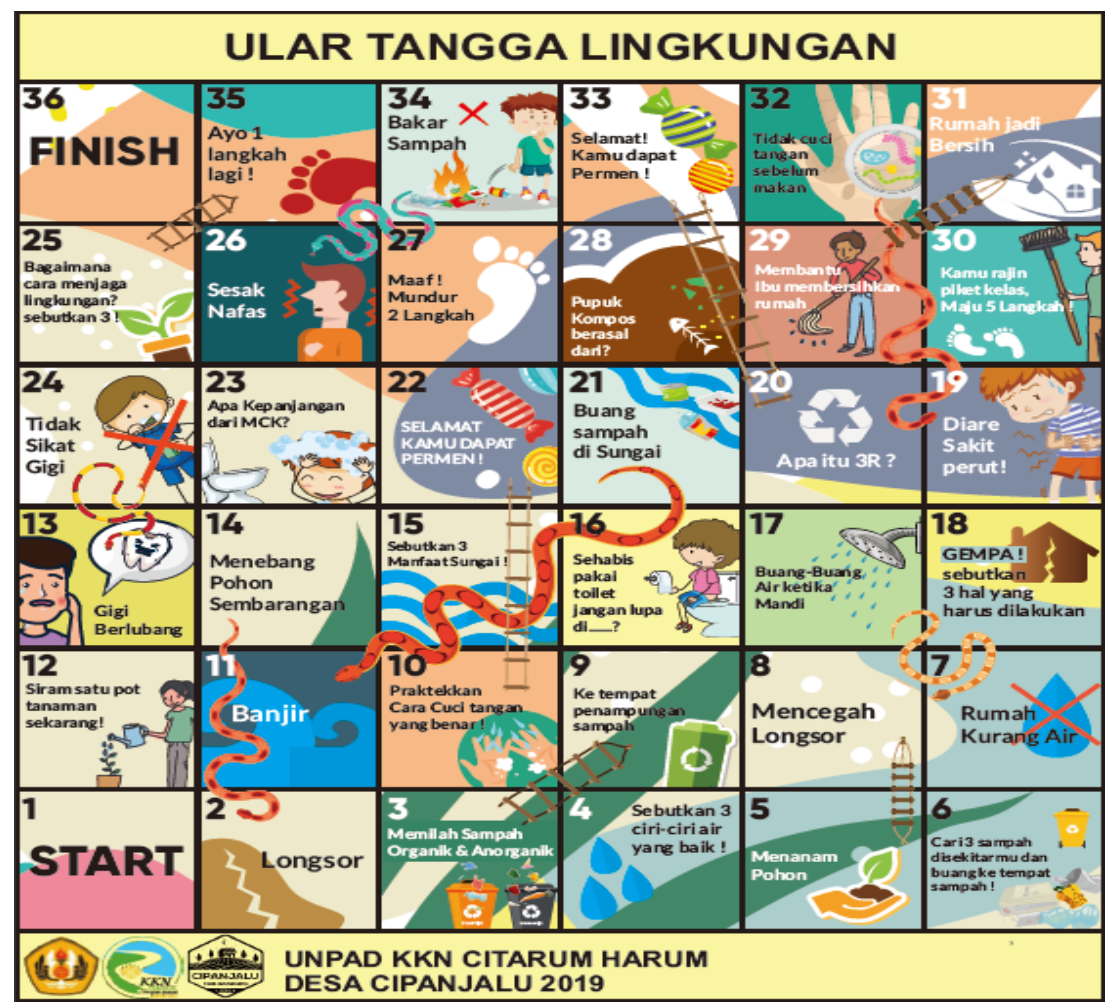

Sumber: (Rahman, dkk 2019) 
Pada prinsipnya permainan ular tangga menggunakan aturan yang sama dengan permainan ular tangga secara umum. Yang membedakan adalah konten permainan yang berisi informasi terkait isu lingkungan. Permainan ini bukan hanya mengajak siswa aktif bergerak di luar kelas, namun mensosialisasikan kepedulian terhadap isu-isu lingkungabn strategis yang ada di Desa Cipanjalu.

Proses disain game edukasi ini menggunakan berbagai macam informasi yang diolah dari data primer dan data sekunder, serta konsultasi Tim dengan kepala sekolah dan guru SDN Pasriluhur serta DPL dari Unpad. Pelaksanaan sosialisasi kepedulian lingkungan melalui game edukasi dilaksanakan dengan siswa kelas 5 SD yang kebetulan memiliki jadwal sesuai dengn program. Sebakum melakukan permainan, siswa dibagi ke dalam 5 kelompok dan diberikan pelajaran singkat yang partisipatif dari mahasiswa KKN Unpad. Untuk melatih kerjasama dan kekompakan Tim setiap kelompok didampingi 1 mhasiswa yang membantu memahami isu lingkungan serta proses dinamika kelompok.

Setelah siswa dianggap siap, anak-anak diminta keluar kelas dan mulai saking memperkenalkan Tim mereka berikut yel-yel kelompok. Selanjutnya, permainan llar tangga lingkungan dimulai. Seluruh siswa berkeliling papan permainan dan memperhatikan instulsi dsmbil aktif bermain. Hanya 5 siswa yg masuk ke arena papan permainan dlaam satu masa. Siswa tersebut harus membacakan insttruksi dalam papan permainan sesuai dengan nomor yang dipijak. Tim yang lain membantu memnjawab pertanyaan atau ikut aktif bermain sesuai perintah. Apabila ada siswa yang menginjak ekor ular, siswa tersebut harus kluar lapangan dan digantui teman satu tim. Tim peenang adalah tim yang jumlah pemainnya terbanyak dan sampai pada papan finish terlebih dahulu.

Gambar 7. Pelaksanaan Sosialisasi Isu Lingkungan melalui Game Ular Tangga di SDN Pasir Luhur, Desa Cipanjalu, Kecamatan Cilengkrang

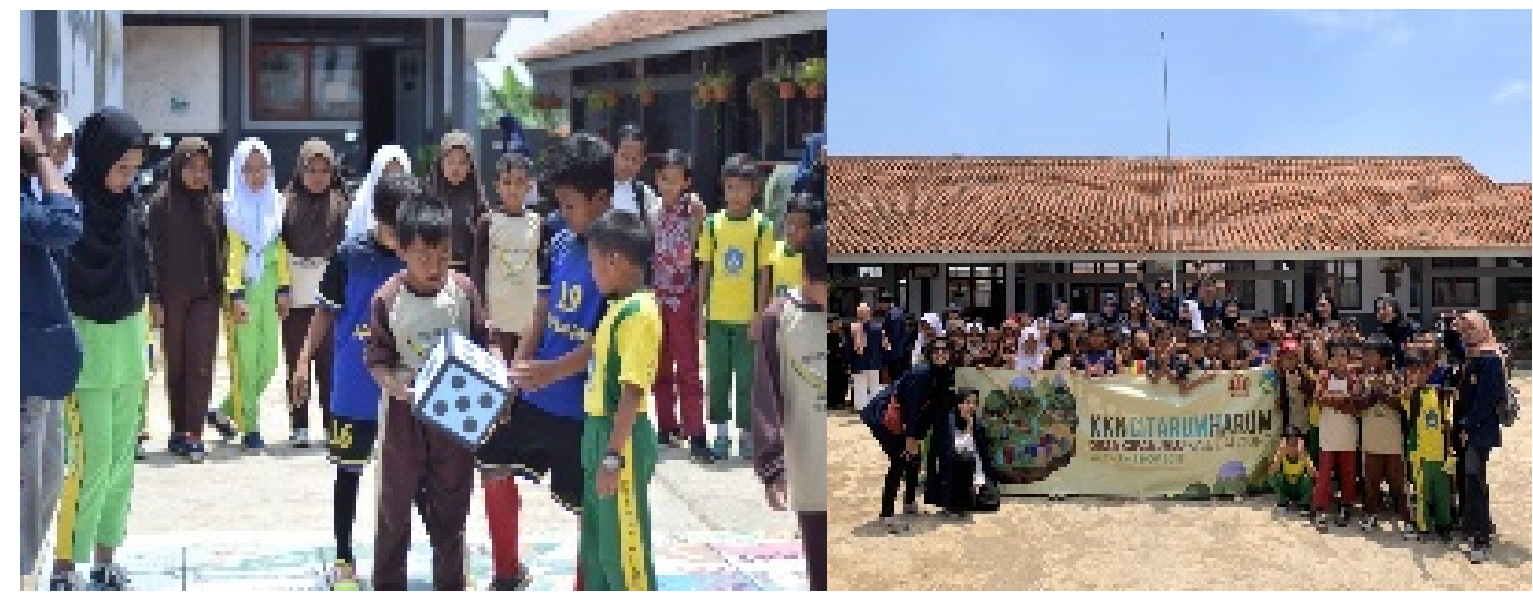




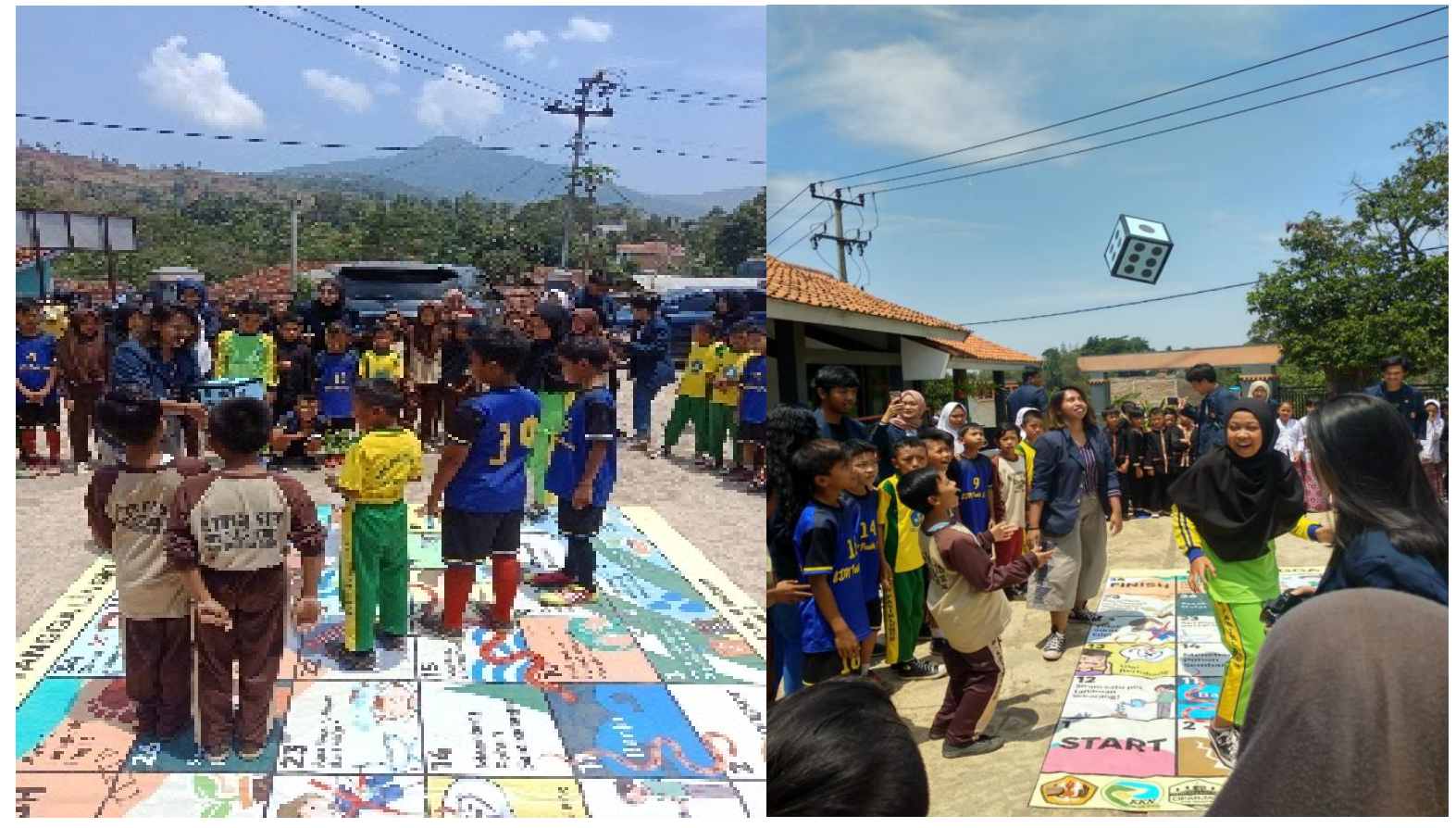

Sumber: (Rahman dkk, 2019)

Permainan berlangsung sekitar 2 jam, semua siswa terlibat aktif dan ceria. Mereka sangat senang mengikuti kegiatan ini, bahkan siswa kelas lain menanyakan kapan mereka boleh ikut bermain. Guru-guru juga memberikan respon positif atas ide permainan edukasi ini, pada akhir acara Tim Unpad menyerahkan alat ermainan edukasi ke sekolah agar dapat dipakai untuk kegiatan serupa di masa yang akan dating.

\section{SIMPULAN}

Walaupun kegiatan KKN Tematik Citarum Harum Universitas Padjadjaran tahun 2019 yang dilaksanakan di di Desa Cipanjalu, Kecamatan Cilengkrang Kabupaten Bandung Cangkuang Wetan dilaksanakan dalam waktu yang pendek, mahasiswa KKN dapat dapat menyumbangkan gagasan praktis terkait upaya percepatan penanganan kerusakan DAS Citarum.

Mahasiswa melakukan Rapid Appraisal atas 5 isu lingkungan strategis di Desa Cipanjalu, dan mengolahnya menjadi sebuah alat edukasi lingkungan bagi siswa SD. Permainan Ular Tangga dipilih mengingat game tersebut merupakan permainan yang mudah dilakukan dan dapat melibatkan banyak Siswa. Informasi penyadaran lingkungan diadaptasi dalam permainan Ular Tangga Lingkungan berdasarkan hasil survey, studi literatur dan benchmarking I proses. Melalui permainan sederhana dan menyenangkan, diharapkan pesan pentingnya menjaga lingkungan hidup dan hidup bersih dapat tercapai. 
Tim KKN KKN Tematik Citarum Harum Universitas Padjadjaran di Desa Cipanjalu berharap agar pihak sekolah dapat menggunakan alat permainan edukasi tersebut untuk meneruskan sosialisai isu lingkungna dan sanitasi.

\section{UCAPAN TERIMAKASIH}

Ucapan terimakasih disampaikan pada Rektor Universitas Padjadjaran, Dirjen Belmawa Kemenristekdikti, Satgas Citarum Harum, Subsektor 21 Citarum Harum., Camat dan aparat Kecamatan Cilengkrang, Kepala dan Aparat Desa Cipanjalu, Tokoh Masyarakat, Penggiat Posyandu Desa Cipanjalu, Para pengajar dan KEpala Sekolah SDN Pasir Luhur serta siswa SDN Pasirluhur yang telah membantu mendukung terselenggaranya kegiatan KKN Tematik Citarum Harum. Terkhusus ucapan terima kasih disampaikan pada Tim Mahasiswa KKN Tematik Citarum Harum Unpad 2019 yang ditempatkan di Desa Cipanjalu yaitu Dwiki Ramadhan R., Nadhif Aditia Aryantaeyla Putri Awalia, Reizandy Ramadhika, Riduwan Ibrahim, Dheva Nugraha P., M. Zidan Ardiansyah, Afriliyendra Putri B., Kagungna Haq, Ferrin Salsabila, Alma Yunira, Chiquitita Qinthar A., Vashty Marwa, R. Hana Majesta Saleh, Yasmin Putrialifa, Rasyidan Aufar D., Nahdhiyah, Syifa Sharifa R., Nisfi Setiawati, dan Sifa Ginuluran

\section{DAFTAR PUSTAKA}

Agus, W. (2018). Penanganan Citarum Berkesinambungan. Http://KoranSindo.Com/Page/News/2018-03-05/5/10/Penanganan_Citarum_Berkesinambungan.

Een, I. (2018). Menaruh Harap pada Keberhasilan Program Citarum Harum.

DRPM Unpad, 2019a, Pedoman Pelaksanaan KKN Tematik Citarum Harum Unpad 20019.

McIntyre, J. (2002). Critical systemic praxis for social and environmental justice: A case study of management, governance, and policy. Systemic Practice and Action Research. https://doi.org/10.1023/A:1014237603948

Parikesit, Takeuchi, K., Tsunekawa, A., \& Abdoellah, O. S. (2001). Non-forest fuelwood acquisition and transition in type of energy for domestic uses in the changing agricultural landscape of the Upper Citarum Watershed, Indonesia. Agriculture, Ecosystems and Environment, 84(3), 245 - 258. https://doi.org/10.1016/S01678809(00)00243-7

Rahman, dkk, 2019, Laporan KKN Tematik Citarum Harum Unpad 2019, -Tidak 
dipuoblikasikan

Samekto, C., \& Rahmadiyanto, C. (2016). Collaboration Dynamics in Integrated Water Resources Management (The University of Queensland). https://doi.org/10.14264/uql.2016.465

Sarminingsih, A. (2007). Evaluasi kekritisan lahan daerah aliran sungai (DAS) dan mendesaknya langkah-langkah konservasi air. Jurnal Presipitasi, 2(1), 8-14.

Satgas Citarum Harum, 2019, Rencana Aksi Nasional Percepatan Penanggulangan Kerusakan DAS Citarum, tidak dipublikasikan

Suharyanto, \& Matsushita, J. (2011). A preliminary assessment towards integrated BBWQM through priority analysis in the UCR Basin, Indonesia. Procedia Environmental Sciences, 4, 331-335. https://doi.org/10.1016/j.proenv.2011.03.038

Tashakkori, A., Teddlie, C., Tashakkori, A., \& Teddlie, C. (2015). Epilogue: Current Developments and Emerging Trends in Integrated Research Methodology. In SAGE Handbook of Mixed Methods in Social \& Behavioral Research. https://doi.org/10.4135/9781506335193.n31

Widianingsih, I., \& Morrell, E. (2007). PARTICIPATORY PLANNING IN INDONESIA. Policy Studies, Vol. 28, pp. 1-15. https://doi.org/10.1080/01442870601121320

Yallop, O. (2014). Citarum, the most polluted river in the world? Telegraph. Retrieved from https://www.telegraph.co.uk/news/earth/environment/10761077/Citarum-the-mostpolluted-river-in-the-world.html\%0Ahttp://ewastemonitor.info/pdf/Regional-EWaste-Monitor.pdf 